\title{
Dopamine induces LTP differentially in apical and basal dendrites through BDNF and voltage-dependent calcium channels
}

\author{
Sheeja Navakkode, ${ }^{1,3}$ Sreedharan Sajikumar, ${ }^{1}$ Martin Korte, ${ }^{1}$ and Tuck Wah Soong ${ }^{2,3}$ \\ ${ }^{1}$ Division of Cellular Neurobiology, Zoological Institute, Braunschweig D-38106, Germany; ${ }^{2}$ Department of Physiology, Yong Loo Lin \\ School of Medicine, National University of Singapore, Singapore 117597
}

\begin{abstract}
The dopaminergic modulation of long-term potentiation (LTP) has been studied well, but the mechanism by which dopamine induces LTP (DA-LTP) in CAl pyramidal neurons is unknown. Here, we report that DA-LTP in basal dendrites is dependent while in apical dendrites it is independent of activation of L-type voltage-gated calcium channels (VDCC). Activation via NMDAR is critical for the induction of DA-LTP in both apical and basal dendrites, but only BDNF is required for the induction and maintenance of DA-LTP in apical dendrites. We report that dopaminergic modulation of LTP is lamina-specific at the Schaffer collateral/commissural synapses in the CAl region.
\end{abstract}

In the hippocampus, afferent inputs to the hippocampus CA1 occur via two major pathways, the temporoammonic and the Schaffer collateral/commissural fibers. Among these, the Schaffer collateral/commissural fibers from the CA3 region synapse on both the apical dendrites in the stratum radiatum (str. radiatum) and the basal dendrites in the stratum oriens (str. oriens).

Studies of long-term potentiation (LTP) in the hippocampal slices both in vitro and in vivo have shown that the threshold for inducing LTP is lower in basal dendrites in comparison to apical dendrites (Kaibara and Leung 1993; Leung and Shen 1995; Sajikumar et al. 2007; Stramiello and Wagner 2010; Sajikumar and Korte 2011a). The CA1 region receives a variety of neuromodulatory inputs including the dopaminergic, cholinergic, and noradrenergic pathways (Otmakhova and Lisman 2000; Leung et al. 2003), and the distributions of these neuromodulatory inputs are not uniform. For example, the hippocampus receives dispersed cholinergic innervations with the highest density of cholinergic axons in the str. oriens and principal cell layer (Arai et al. 1994; Gasbarri et al. 1994b; Aznavour et al. 2002), and anatomical studies suggest that, not only the str. radiatum but also the str. oriens, is innervated by dopaminergic projections from the meso-limbo-cortical system (Verney et al. 1985; Gasbarri et al. 1994a,b)

The neuromodulatory influences in the str. radiatum and str. oriens regions are also different. One example of a spatially restricted effect of a neuromodulatory neurotransmitter is the action of acetylcholine on the muscarinic acetylcholine receptors. Cholinergic activation by carbachol produces a significantly stronger suppression of synaptic transmission at the CA3-CA1 synapses of the proximal apical dendrites, while being less effective at synapses of the apical tuft (Hasselmo and Schnell 1994). This cholinergic suppression has been shown to enhance associative memory functions (De Rosa and Hasselmo 2000). In neocortical pyramidal neurons, pairing of excitatory post-synaptic potentials (EPSPs) and action potentials (Gordon et al. 2006) leads to the potentiation of synapses at the proximal basal dendrites but

\footnotetext{
${ }^{3}$ Corresponding authors

E-mail phsstw@nus.edu.sg

E-mail sheejanavakkode@yahoo.com.uk

Article is online at http://www.learnmem.org/cgi/doi/10.1101/Im.026203.112.
}

not the distal basal dendrites. In the distal basal dendrites, synaptic potentiation occurs only when synaptic activation (which is strong enough to evoke an NMDA spike) is paired with BDNF application (Gordon et al. 2006). Even within the apical dendrites, the plasticity thresholds for inducing LTP and LTD are different in distal and proximal regions (Parvez et al. 2010; Sajikumar and Korte 2011a).

Persistence of long-term memory depends on the activation of the ventral tegmental area (VTA)/hippocampus dopaminergic connections (Rossato et al. 2009). Dopamine also regulates the expression of proteins essential for the establishment of long-lasting neuronal plasticity like brain-derived neurotrophic factor (BDNF), and this requires NMDA-receptor activity (Kuppers and Beyer 2001). A D1-receptor-dependent increase in BDNF determines the duration of long-term memory (LTM) (Rossato et al. 2009). Cocaine withdrawal is also known to facilitate LTP in medial prefrontal cortex by elevating BDNF levels. After repeated cocaine withdrawal, excitatory synapses onto VTA dopamine neurons become highly sensitive to LTP induction (Pu et al. 2006).

D1-receptor stimulation also induces a long-lasting increase in basal calcium levels from intracellular stores and also via voltage-gated calcium channels (Ming et al. 2006). L-type $\mathrm{Ca}^{2+}$ channel immunoreactivity has been observed primarily in the soma, basal, and proximal apical dendrite compartments (Tippens et al. 2008). D1/D5-receptor activation can potentiate L-type $\mathrm{Ca}^{2+}$ channels, and this activation by D1/D5-receptor agonists is mediated by cAMP-dependent protein kinase A, as shown in chromaffin cells (Artalejo et al. 1990).

Exogenous application of dopaminergic agonists or dopamine itself can modulate the persistence of LTP in apical dendrites (Huang and Kandel 1995; Navakkode et al. 2007, 2010). However, in contrast to this apical LTP, dopaminergic modulation of LTP within the basal dendrites has not received much attention. Therefore, we set out to investigate whether application of dopamine could induce late-LTP in basal dendrites. We could show that, similar to apical dendrites, dopamine induces a slow onset and long-lasting potentiation (Dopamine induced LTP or DA-LTP). The DA-LTP induction in basal and apical dendrites requires $N$-methyl-D-aspartic acid-receptor (NMDAR) activation. Interestingly, BDNF is only required for the induction and maintenance of DA-LTP in apical dendrites. We also examined whether the L-type voltage-gated calcium 
channels (L-VDCCs) are critical for the induction of DA-LTP in basal dendrites, while L-VDCCs are not required for DA-LTP in apical dendrites.

All procedures were done according to the guidelines of the Institutional Animal Care \& Use Committee (IACUC), National University of Singapore, Singapore and Animal Committee on Ethics in the Care and Use of Laboratory Animals of TUBraunschweig, Germany. We used 101 transverse hippocampal slices (400- $\mu$ m thick), prepared from 101 male Wistar rats (6- to 7 -wk-old). Slice preparation, incubation, and recordings were conducted according to the protocol reported in our earlier publications (Sajikumar et al. 2005, 2009; Navakkode et al. 2007).

Late-LTP was induced in basal or apical dendrites using a strong tetanization (STET) protocol consisting of three stimulus trains of 100 pulses, $100 \mathrm{~Hz}$ duration, $0.2 \mathrm{msec} /$ polarity, and intertrain interval of $10 \mathrm{~min}$ (Sajikumar et al. 2005). Four 0.2-Hz-biphasic constant current pulses $(0.1 \mathrm{msec} /$ polarity) were used for baseline recording and were delivered at 1, 3, 5, 11, 15, 21, 25, 30 , and every $15 \mathrm{~min}$ thereafter and continued until $4 \mathrm{~h}$ or $6 \mathrm{~h}$.

Dopamine was used at a concentration of $50 \mu \mathrm{M}$ (Tocris Cookson). It was dissolved in ACSF containing the antioxidant, ascorbic acid (ROTH), at $1-\mathrm{mM}$ concentration, which had no effect on basal synaptic transmission (Navakkode et al. 2007). AP-V or nifedipine (Tocris) was used at a concentration of $50 \mu \mathrm{M}$ and $10 \mu \mathrm{M}$, respectively (dissolved in ACSF and 0.1\% DMSO).
TrkB/Fc, a BDNF scavenger, was used at a concentration of $1 \mu \mathrm{g} /$ mL (R\&D Systems) (Navakkode and Korte 2012). It was dissolved as a stock solution in $0.1 \%$ BSA and aliquoted in small volumes at $-20^{\circ} \mathrm{C}$

The average values of the population spike $(\mathrm{mV})$ and slope function of the Field-EPSP $(\mathrm{mV} / \mathrm{msec})$ per time point were subjected to the Wilcoxon signed rank test when compared within one group or the Mann-Whitney- $U$-test, when data were compared between groups (significant difference was set at $P<0.05$ ).

It has been reported earlier that application of D1/D5-receptor agonist or dopamine itself can induce a slow onset potentiation in the apical dendrites of CA1 pyramidal cells (Huang and Kandel 1995; Navakkode et al. 2007; Navakkode and Korte 2012). Consistent with these results, we examined whether or not dopamine can induce slow onset potentiation lasting for at least $4 \mathrm{~h}$ (DA-LTP) in apical dendrites $(n=7)$ (Fig. 1B). The fEPSP values showed statistically significant potentiation from $25 \mathrm{~min}$ (Wilcoxon test, $P=0.02$ ) onwards and then remained stable for the recorded time period of $4 \mathrm{~h}$. Next, we determined whether dopamine can induce long-lasting LTP in the basal dendrites. Similar to apical dendrites, dopamine induced a slow onset, longlasting LTP for $4 \mathrm{~h}$ in basal dendrites $(n=7)$ (Fig. 1E). In all experiments, after a 1-h stable baseline, dopamine $(50 \mu \mathrm{M})$ was bathapplied in three pulses for $5 \mathrm{~min}$ at $10 \mathrm{~min}$ intervals, together with ascorbic acid, an antioxidant, at a concentration of $1 \mathrm{mM}$.
A

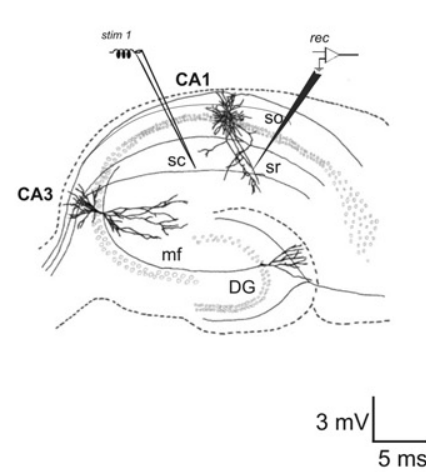

B

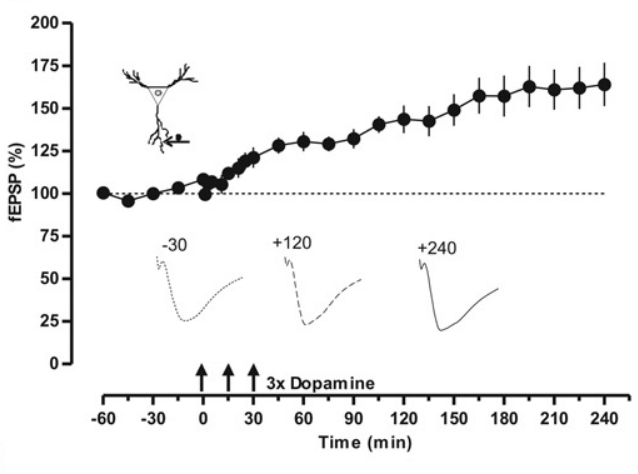

$E_{200}$

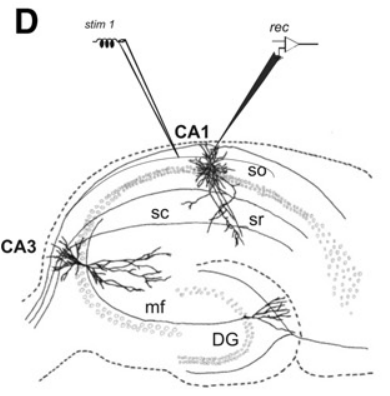

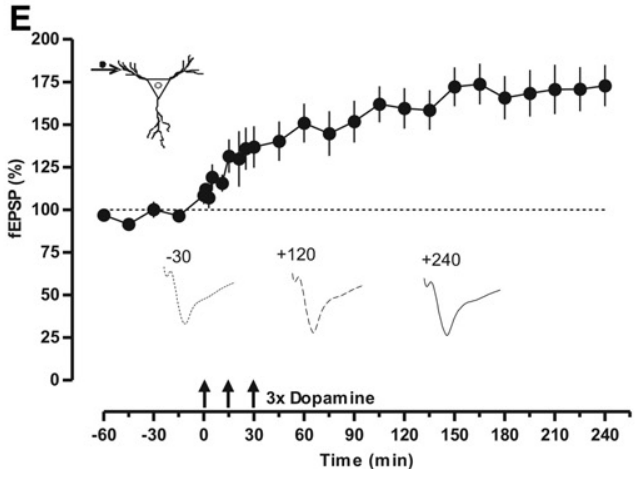

C
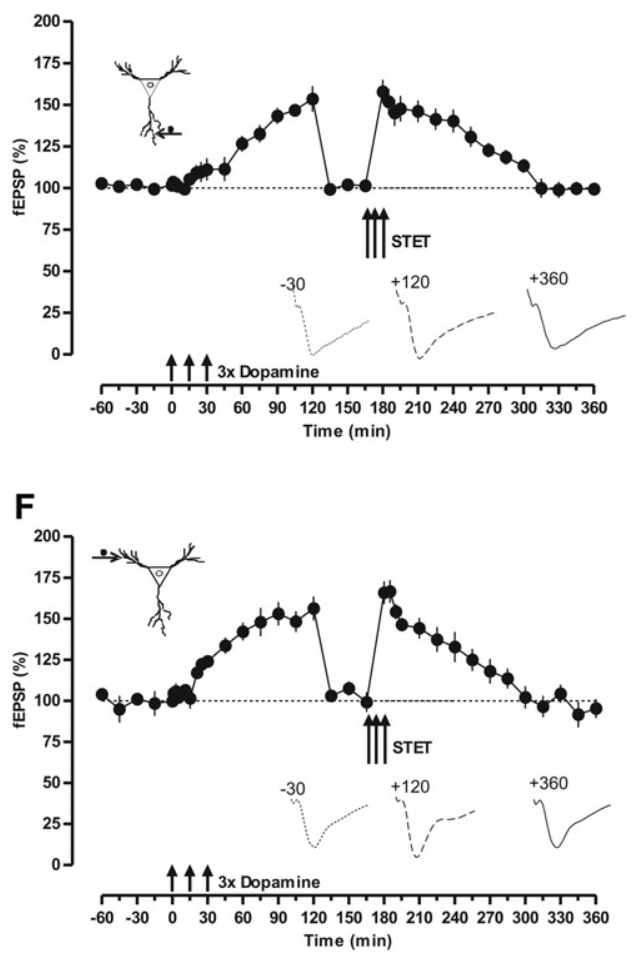

Figure 1. Dopamine induces LTP in basal and apical dendrites of CA1 pyramidal neurons. $(A, D)$ Schematic representation of electrode location in the apical or basal dendrites of hippocampal slices for recording long lasting potentiation from CA1. Stim 1 represents the stimulating and rec represents the recording electrode in the stratum radiatum. $(B, E)$ Dopamine $(50 \mu \mathrm{M})$ was coapplied with the antioxidant ascorbic acid $(1 \mathrm{mM})$ in three pulses for 5 -min at 10-min intervals in apical or basal dendrites, respectively. Dopamine induces a slow onset, long-lasting LTP for up to 240 min in apical ( $n=7$ ) or basal dendrites $(n=7)$. $(C, F)$ Dopamine-induced LTP was maintained for a duration of 120 min, and the stimulation intensity was adjusted to baseline level and recorded a stable baseline for $30 \mathrm{~min}$. A strong tetanization protocol (STET) was applied for inducing late-LTP at 180 min in apical or basal dendrites, respectively, and maintained for $6 \mathrm{~h}$. Potentials decayed to baseline within $\sim 300$ min in apical $(n=8)$ or basal dendrites $(n=8)$; thus dopamine-induced LTP occludes STET-induced late-LTP. Insets in graphs represent typical field EPSP traces per stimulated input 30 min before (dotted lines), 120 min after (broken line), and 240 or 360 min (continuous line) after LTP induction. Data are expressed as mean SEM. Arrows represent the time point of application of the drug or STET. The cartoon of a neuron presented in each graph shows the site of application of dopamine in apical or basal dendrites. Calibration bar for all analogs: $3 \mathrm{mV} / 5 \mathrm{msec}$. 
The fEPSP in Figure 1E showed statistically significant potentiation from $25 \mathrm{~min}$ (Wilcoxon test, $P=0.02$ ) onwards and then remained significant for $4 \mathrm{~h}$ (Wilcoxon test, $P=0.02$ ). We were interested to know whether DA-LTP shares common mechanisms with tetani-induced LTP in apical and basal dendrites. To address this question, first we induced DA-LTP in apical and basal dendrites and maintained for $120 \mathrm{~min}$ (Fig. 1C,F), after which the stimulation intensity was adjusted to baseline level and recorded a stable baseline for $30 \mathrm{~min}$. Strong high frequency stimulation (STET) was delivered at the 180th min to the apical or basal dendrites (Fig. 1C,F), thus electrical induction protocols could induce early LTP but not late-LTP. The LTP in apical and basal dendrites decayed to baseline at $300 \mathrm{~min}$ in basal dendrites (Wilcoxon test, $P>0.05, n=8$ ) and at $270 \mathrm{~min}$ in apical dendrites (Wilcoxon test, $P>0.05, n=8$ ).

NMDAR activation was necessary for the induction of DA-LTP in apical dendrites (Navakkode et al. 2010). Consistent with these findings, we found that coapplication of NMDAR antagonist AP-V $(50 \mu \mathrm{M})$, along with dopamine, completely abolished LTP in basal dendrites $(n=8)$ (Fig. 2A). In order to address the involvement of calcium channels in DA-LTP, we coapplied dopamine with an L-type VDCC antagonist, nifedipine $(10 \mu \mathrm{M})$, either on the apical dendrites or the basal dendrites. As is evident from Figure $2 \mathrm{~B}(n=6)$, nifedipine did not exert any effects on DA-LTP in apical dendrites, while in basal dendrites, DA-LTP was completely prevented $(n=10)$ (Fig. 2C). The fEPSP in apical dendrites showed statistically significant potentiation from 25 min onwards compared to its own baseline (Wilcoxon test, $P=$ 0.02). In basal dendrites, there was no significant potentiation when compared to the baseline controls (Wilcoxon test, $P>$ $0.05)$.

Dopamine is known to facilitate LTP and long-term memory by increasing BDNF levels in vivo (Rossato et al. 2009), In this context, we investigated whether DA-LTP requires BDNF for its induction and persistence in apical and basal dendrites . To evaluate the role of BDNF, we used a BDNF scavenger, TrkB/Fc $(1 \mu \mathrm{g} / \mathrm{mL})$. After recording a stable baseline for $30 \mathrm{~min}$, TrkB/Fc was bathapplied initially for $30 \mathrm{~min}$ and then coapplied with dopamine (a total of $1 \mathrm{~h} \mathrm{TrKB} / \mathrm{Fc}$ application time) in apical or in basal dendrites. Interestingly, TrKB/Fc prevented DA-LTP in apical dendrites $(n=8)$ (Fig. 3A) but not in basal dendrites $(n=8)$ (Fig. $3 \mathrm{~B})$. Next, we examined the effect of BDNF inhibition at two time points, 60 or $180 \mathrm{~min}$, after initial dopamine application (Fig. 3C-F). Continuous inhibition of BDNF by TrKB/Fc starting at 60 or $180 \mathrm{~min}$ either in apical or basal dendrites interfered with the maintenance of DA-LTP only in apical dendrites $(n=8$ for each) (Fig. 3C,E) but not in basal dendrites ( $n=6$ and $n=8$, respectively) (Fig. 3D,F). TrkB-Fc application decreased the level of potentiation from $105 \mathrm{~min}$ onward ( $U$-test, $P=0.02$ ) when compared to control DA-LTP in apical dendrites (Fig. 3C) and

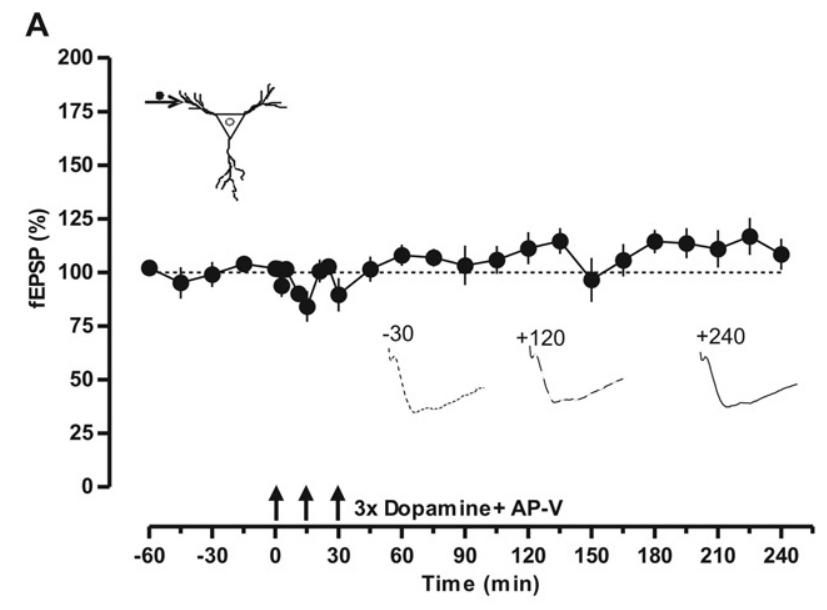

B

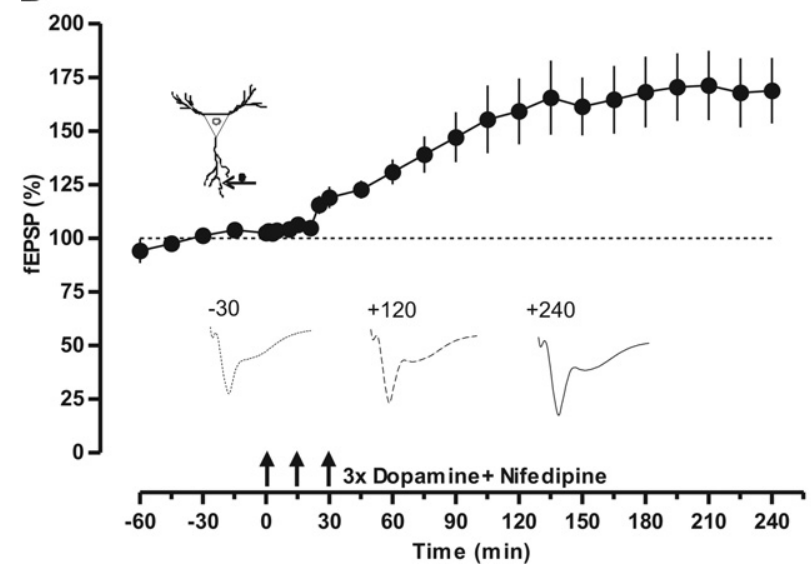

C

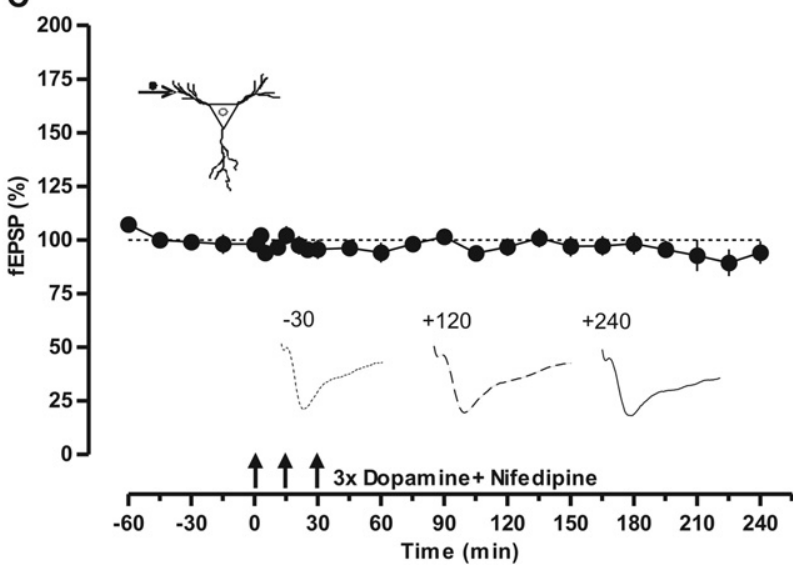

Figure 2. Induction requirements of dopamine LTP in basal or apical dendrites. (A) Coapplication of NMDAR antagonist D-AP-V (50 $\mu$ M) with dopamine prevents induction of dopamine LTP in basal dendrites $(n=7)$. (B) Coapplication of L-type calcium channel antagonist nifedipine $(10 \mu \mathrm{M})$ with dopamine had no inhibitory effect on dopamine-induced LTP in apical dendrites $(n=6)$. (C) The same experiment as in $B$ but repeated in basal dendrites. Here, nifedipine prevents dopamine-induced LTP $(n=10)$. Symbols and traces are as in Figure 1. 
A

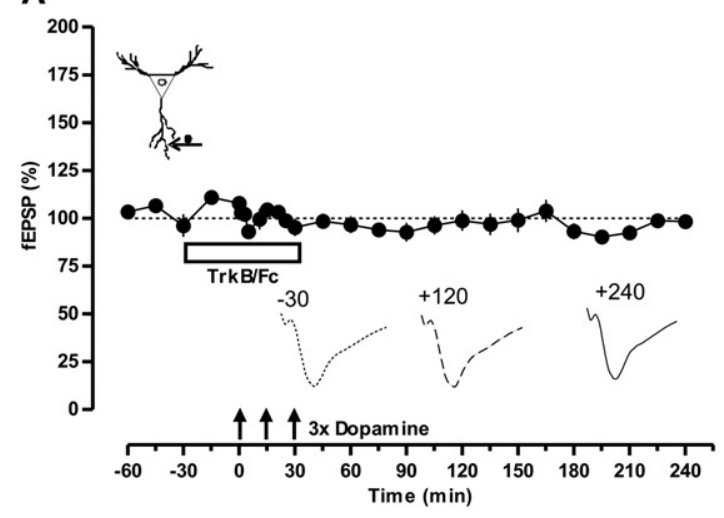

C

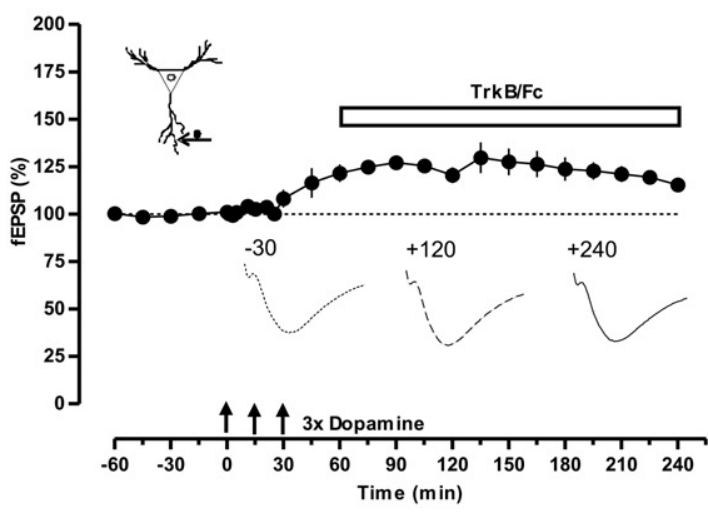

E

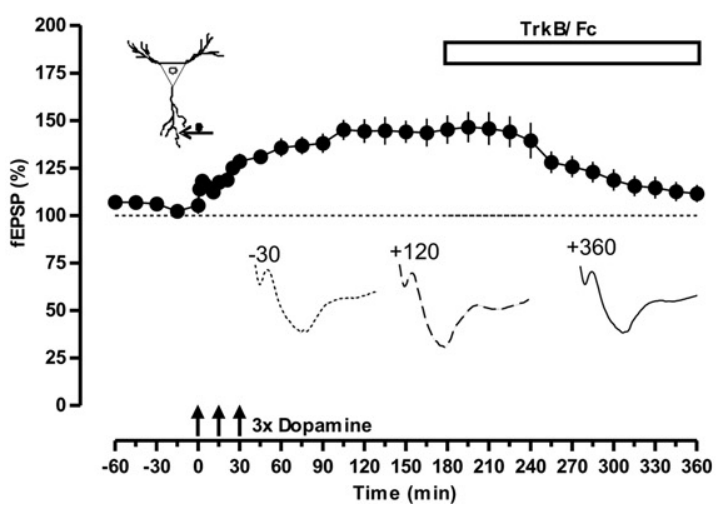

B

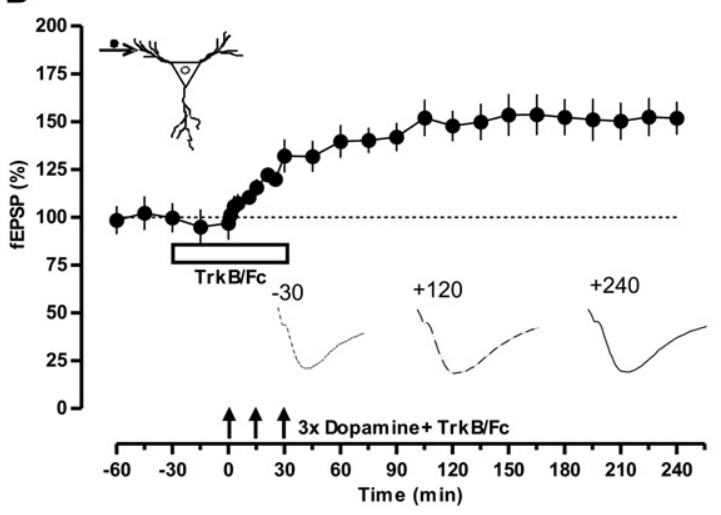

D

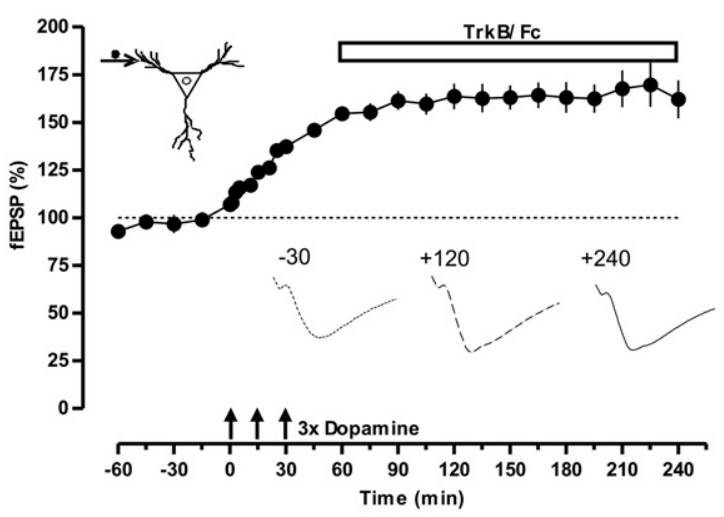

$\mathbf{F}$

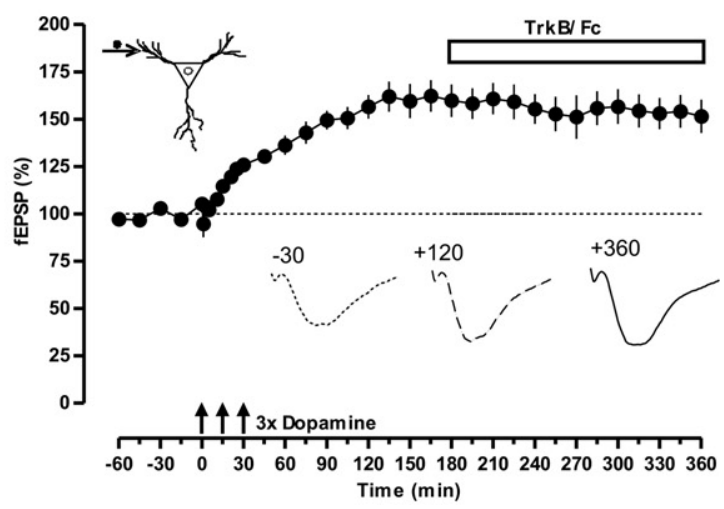

Figure 3. Dopamine-induced LTP in basal and apical dendrites have different mechanisms for its persistence. $(A, B)$ After recording a stable baseline of $30 \mathrm{~min}$, TrkB/Fc was bath-applied initially for $30 \mathrm{~min}$ and then coapplied with dopamine (a total of $1 \mathrm{~h}$ TrKB/Fc application time) in apical or in basal dendrites. TrKB/Fc prevented the induction of LTP in apical dendrites $(n=8)$ but not in basal dendrites $(n=8)$. $(C, D)$ Continuous inhibition of BDNF by TrKB/Fc starting at $60 \mathrm{~min}$ after the initial application of dopamine interfered with the maintenance of LTP in apical dendrites $(n=8)$ but not in basal dendrites $(n=8)$. $(E, F)$ Continuous inhibition of BDNF by TrKB/Fc starting at 180 min after the initial application of dopamine interfered with the maintenance of LTP in apical dendrites $(n=8)$ but not in basal dendrites $(n=8)$. Open bar represents the time point of TrkB-Fc application. Symbols and traces are as in Figures 1 and 2.

240 min onward in Figure 3E ( $U$-test, $P=0.02$ ). Statistically significant potentiation was observed from $30 \mathrm{~min}$ (Wilcoxon test, $P=$ 0.02) onward and then remained significant for $4 \mathrm{~h}$ or $6 \mathrm{~h}$ in the basal dendrites (Fig. 3D,F).

Our results showed that the activation of dopaminergic receptors by dopamine could induce long-lasting LTP in both apical and basal dendrites of the CA1 pyramidal cells, and these forms of LTP are similar in their mechanism to that of electrically induced late-LTP (Huang and Kandel 1995; Sajikumar and Frey 2004).
Although DA-LTP in both apical and basal dendrites required NMDAR activation, similar to that of electrically induced lateLTP (Arai et al. 1994; Haley et al. 1996), we observed that, in addition to NMDAR, L-type VDCC activation was also required for DA-LTP in basal dendrites. These findings are in agreement with the earlier report that the threshold for inducing LTP differed in the CA1 pyramidal neurons. For instance, a weak stimulation in distal apical dendrites resulted in protein synthesis-independent LTP, while the same stimulation resulted in long-lasting protein 
synthesis-dependent late-LTP in proximal apical dendrites (Sajikumar and Korte 2011a). The plasticity threshold in str. oriens may differ in comparison to str. radiatum due to its morphology and biophysical properties. For instance, GABAergic and retrograde messenger nitric oxide $(\mathrm{NO})$ requirements are less in str. oriens compared to str. radiatum (Toth and Freund 1992; Haley et al. 1996). These differences could play an important role in the integration of afferent inputs in CA1 pyramidal neurons. By knowing the difference in apical and basal dendrites, one would expect that dopamine modulation might be stronger in basal dendrites, and it might induce a higher percentage of potentiation. However, our studies showed that DA-LTP in both regions was of similar magnitude, indicating that dopamine might exert its effects almost similarly in the two regions with some exceptions in induction and maintenance (see below).

It was hypothesized that D1/D5-receptors might enhance potentiation by three different mechanisms (Otmakhova and Lisman 1996; Raman et al. 1996). On the one hand, dopamine might cause an enhancement of LTP by increasing depolarization (Yang and Seamans 1996) and, on the other hand, by enhancing the NMDA receptors that are critical for LTP induction (Raman et al. 1996). In addition, substantial biochemical evidence suggests that cAMP metabolism is powerfully controlled by neuromodulators (Cooper et al. 1995). Apart from the effect of neuromodulators, induction of LTP also requires calcium influx into post-synaptic neurons through ligand-gated NMDA-receptors and also through voltage-dependent calcium channels. Nifedipine is known to substantially reduce LTP in the presence of $\mathrm{AP}-5$, and this points to the fact that L-type VDCCs participate in the induction of NMDA-receptor-independent LTP in the CA1 area (Grover et al. 2009). As VDCCs and NMDA receptors underlie two forms of LTP in the hippocampus (Artalejo et al. 1990), dopamine might act together with the activation of NMDAR and L-type VDCCs or in an NMDA-receptor-dependent manner. Our results revealed that DA-LTP induction in basal dendrites required both NMDAR and L-type VDCCs, while apical dendrites were independent of L-type VDCCs for DA-LTP. This view is strengthened by our earlier findings that dopamine-LTP in apical dendrites was NMDA-receptor-dependent (Navakkode et al. 2010), and synergistic activity of D1/D5 and NMDAR function was required for the induction and maintenance of DA-LTP apical dendrites (Navakkode et al. 2007, 2010). It is also important to note that, as reported, dopaminergic function in hippocampal CA1 is to modulate synaptic responses rather than the activation of the machinery required to induce protein synthesis-dependent L-LTP (Mockett et al. 2004). This discrepancy in the mechanisms of dopaminergic activation has been addressed in our recent reports (Navakkode et al. 2007, 2010). Similar to NMDA-receptor-dependent LTP, long-term memory also depends on the activation of VTA/hippocampus dopaminergic connections and can be specifically modulated by manipulating this system. Both BDNF and TrkB-receptors are expressed by the dopaminergic neurons and dopamine modulates LTP and LTM by regulating the expression of proteins like BDNF (Rossato et al. 2009) and PKM $\zeta$ (Navakkode et al. 2010), which are essential for the establishment of long-lasting plasticity (Korte et al. 1998; Ling et al. 2002).

Our studies show that inhibiting BDNF-mediated actions prevents DA-LTP only in apical dendrites without affecting the induction and maintenance of DA-LTP in basal dendrites. Thus, the L-type VDCC and NMDR-dependent DA-LTP in basal dendrites follows a signaling pathway independent of BDNF, while the NMDA-receptor-dependent DA-LTP in apical dendrites in dependent on BDNF. It had been reported earlier that BDNF inhibition had differential effects on tetani-induced and theta burst stimulation (TBS)-induced LTP (Chen et al. 1999). Importantly, it was suggested that endogenous BDNF was required for a limited time period only shortly before or during LTP induction but not over the whole process of LTP. Our findings are consistent with this study for the requirement of BDNF for induction of DA-LTP. In contrast, we report that BDNF inhibition $60 \mathrm{~min}$ or $180 \mathrm{~min}$ after the establishment of DA-LTP could also prevent its maintenance in apical dendrites. These results support earlier findings that continuous activation of BDNF receptors is necessary for the maintenance of certain forms of late-LTP (Huang and Kandel 1995) and its associativity from tetanized synapses to depressed synapses (cross-tagging) (Sajikumar and Korte 2011b). In addition, continued activation of BDNF receptors was also necessary for the generation of the long-lasting form of LTP induced by glutamatergic and cholinergic activation (Navakkode and Korte 2012).

In general, our data support that tetani-induced late-LTP and dopamine-induced LTP have the following similarities: (1) NMDAR activation and protein synthesis (Navakkode et al. 2010); (2) the BDNF requirement for the long-lasting maintenance of LTP in apical dendrites; and (3) associativity and cooperativeness between strongly activated and weakly activated synapses. Although, associativity is expressed in dopamine-induced LTP (Navakkode et al. 2010), it remains to be investigated how long the cooperative interaction can be maintained with DA-LTP.

The reduced expression of BDNF within the substantia nigra accompanies the deterioration of dopaminergic neurons in Parkinson's disease (PD) patients (Baquet et al. 2005), and activation of L-type calcium channels is required for dopamine release (Mendez et al. 2011). Understanding the mechanism of action of dopamine in different regions of the brain could, therefore, help us to elucidate the etiology of neurodegenerative diseases like PD. The existence of such apical and basal synaptic transmission with different properties has been suggested to provide a higher sensitivity and diversity for synaptic plasticity in the hippocampus (Leung and Shen 1995). The physiological relevance of the differential distribution of neuromodulators, their action, and their differences in LTP threshold is not known. We, therefore, hypothesize that a difference in the balance of synaptic plasticity between different regions might account for how systemrelevant information is coded in neuronal networks for storing memory engrams effectively. In addition, the alternative mechanisms used for neuromodulation in different regions might also render neuroprotection and reduce vulnerability to neurodegenerative diseases.

\section{Acknowledgments}

S.N. and S.S. were supported by Alexander von Humboldt Fellowships. T.W.S was supported by BMRC. This work was also supported by DFG (SA 1853/1-1 to S.S. and M.K.).

\section{References}

Arai A, Black J, Lynch G. 1994. Origins of the variations in long-term potentiation between synapses in the basal versus apical dendrites of hippocampal neurons. Hippocampus 4: 1-9.

Artalejo CR, Ariano MA, Perlman RL, Fox AP. 1990. Activation of facilitation calcium channels in chromaffin cells by D1 dopamine receptors through a cAMP/protein kinase A-dependent mechanism. Nature 348: 239-242.

Aznavour N, Mechawar N, Descarries L. 2002. Comparative analysis of cholinergic innervation in the dorsal hippocampus of adult mouse and rat: A quantitative immunocytochemical study. Hippocampus 12: $206-217$.

Baquet ZC, Bickford PC, Jones KR. 2005. Brain-derived neurotrophic factor is required for the establishment of the proper number of dopaminergic neurons in the substantia nigra pars compacta. J Neurosci 25: $6251-6259$.

Chen G, Kolbeck R, Barde YA, Bonhoeffer T, Kossel A. 1999. Relative contribution of endogenous neurotrophins in hippocampal long-term potentiation. J Neurosci 19: 7983-7990. 
Cooper DM, Mons N, Karpen JW. 1995. Adenylyl cyclases and the interaction between calcium and cAMP signalling. Nature 374: $421-424$.

De Rosa E, Hasselmo ME. 2000. Muscarinic cholinergic neuromodulation reduces proactive interference between stored odor memories during associative learning in rats. Behav Neurosci 114: 32-41.

Gasbarri A, Packard MG, Campana E, Pacitti C. 1994a. Anterograde and retrograde tracing of projections from the ventral tegmental area to the hippocampal formation in the rat. Brain Res Bull 33: 445-452.

Gasbarri A, Verney C, Innocenzi R, Campana E, Pacitti C. 1994b. Mesolimbic dopaminergic neurons innervating the hippocampal formation in the rat: A combined retrograde tracing and immunohistochemical study. Brain Res 668: 71-79.

Gordon U, Polsky A, Schiller J. 2006. Plasticity compartments in basal dendrites of neocortical pyramidal neurons. J Neurosci 26: 12717-12726.

Grover LM, Kim E, Cooke JD, Holmes WR. 2009. LTP in hippocampal area CA1 is induced by burst stimulation over a broad frequency range centered around delta. Learn Mem 16: 69-81.

Haley JE, Schaible E, Pavlidis P, Murdock A, Madison DV. 1996. Basal and apical synapses of CA1 pyramidal cells employ different LTP induction mechanisms. Learn Mem 3: 289-295.

Hasselmo ME, Schnell E. 1994. Laminar selectivity of the cholinergic suppression of synaptic transmission in rat hippocampal region CA1: Computational modeling and brain slice physiology. J Neurosci 14: 3898-3914.

Huang YY, Kandel ER. 1995. D1/D5 receptor agonists induce a protein synthesis-dependent late potentiation in the CA1 region of the hippocampus. Proc Natl Acad Sci 92: 2446-2450.

Kaibara T, Leung LS. 1993. Basal versus apical dendritic long-term potentiation of commissural afferents to hippocampal CA1: A current-source density study. I Neurosci 13: 2391-2404.

Korte M, Kang H, Bonhoeffer T, Schuman E. 1998. A role for BDNF in the late-phase of hippocampal long-term potentiation. Neuropharmacology 37: $553-559$.

Kuppers E, Beyer C. 2001. Dopamine regulates brain-derived neurotrophic factor (BDNF) expression in cultured embryonic mouse striatal cells. Neuroreport 12: $1175-1179$.

Leung LS, Shen B. 1995. Long-term potentiation at the apical and basal dendritic synapses of CA1 after local stimulation in behaving rats. J Neurophysiol 73: 1938-1946.

Leung LS, Shen B, Rajakumar N, Ma J. 2003. Cholinergic activity enhances hippocampal long-term potentiation in CA1 during walking in rats. J Neurosci 23: 9297-9304

Ling DS, Benardo LS, Serrano PA, Blace N, Kelly MT, Crary JF, Sacktor TC. 2002. Protein kinase $\mathrm{M} \zeta$ is necessary and sufficient for LTP maintenance. Nat Neurosci 5: 295-296.

Mendez JA, Bourque MJ, Fasano C, Kortleven C, Trudeau LE. 2011. Somatodendritic dopamine release requires synaptotagmin 4 and 7 and the participation of voltage-gated calcium channels. J Biol Chem 286: 23928-23937.

Ming Y, Zhang H, Long L, Wang F, Chen J, Zhen X. 2006. Modulation of $\mathrm{Ca} 2+$ signals by phosphatidylinositol-linked novel D1 dopamine receptor in hippocampal neurons. J Neurochem 98: 1316-1323.

Mockett BG, Brooks WM, Tate WP, Abraham WC. 2004. Dopamine D1/D5 receptor activation fails to initiate an activity-independent late-phase LTP in rat hippocampus. Brain Res 1021: 92-100.

Navakkode S, Korte M. 2012. Cooperation between cholinergic and glutamatergic receptors are essential to induce BDNF-dependent long-lasting memory storage. Hippocampus 22: 335-346.

Navakkode S, Sajikumar S, Frey JU. 2007. Synergistic requirements for the induction of dopaminergic D1/D5-receptor-mediated LTP in hippocampal slices of rat CA1 in vitro. Neuropharmacology $\mathbf{5 2}$ $1547-1554$
Navakkode S, Sajikumar S, Sacktor TC, Frey JU. 2010. Protein kinase M $\zeta$ is essential for the induction and maintenance of dopamine-induced long-term potentiation in apical CA1 dendrites. Learn Mem 17: $605-611$.

Otmakhova NA, Lisman JE. 1996. D1/D5 dopamine receptor activation increases the magnitude of early long-term potentiation at CA1 hippocampal synapses. J Neurosci 16: 7478-7486.

Otmakhova NA, Lisman JE. 2000. Dopamine, serotonin, and noradrenaline strongly inhibit the direct perforant path-CA1 synaptic input, but have little effect on the Schaffer collateral input. Ann NY Acad Sci 911: $462-464$.

Parvez S, Ramachandran B, Frey JU. 2010. Functional differences between and across different regions of the apical branch of hippocampal CA1 dendrites with respect to long-term depression induction and synaptic cross-tagging. J Neurosci 30: 5118-5123.

Pu L, Liu QS, Poo MM. 2006. BDNF-dependent synaptic sensitization in midbrain dopamine neurons after cocaine withdrawal. Nat Neurosci 9: 605-607.

Raman IM, Tong G, Jahr CE. 1996. Beta-adrenergic regulation of synaptic NMDA receptors by cAMP-dependent protein kinase. Neuron 16: $415-421$.

Rossato JI, Bevilaqua LR, Izquierdo I, Medina JH, Cammarota M. 2009. Dopamine controls persistence of long-term memory storage. Science 325: $1017-1020$.

Sajikumar S, Frey JU. 2004. Late-associativity, synaptic tagging, and the role of dopamine during LTP and LTD. Neurobiol Learn Mem 82: $12-25$.

Sajikumar S, Korte M. 2011a. Different compartments of apical CA1 dendrites have different plasticity thresholds for expressing synaptic tagging and capture. Learn Mem 18: 327-331.

Sajikumar S, Korte M. 2011b. Metaplasticity governs compartmentalization of synaptic tagging and capture through brain-derived neurotrophic factor (BDNF) and protein kinase $\mathrm{M} \zeta$ (PKM $\zeta)$. Proc Natl Acad Sci 108: 2551-2556.

Sajikumar S, Navakkode S, Frey JU. 2005. Protein synthesis-dependent long-term functional plasticity: Methods and techniques. Curr Opin Neurobiol 15: 607-613.

Sajikumar S, Navakkode S, Frey JU. 2007. Identification of compartmentand process-specific molecules required for "synaptic tagging" during long-term potentiation and long-term depression in hippocampal CA1. J Neurosci 27: 5068-5080.

Sajikumar S, Li Q, Abraham WC, Xiao ZC. 2009. Priming of short-term potentiation and synaptic tagging/capture mechanisms by ryanodine receptor activation in rat hippocampal CA1. Learn Mem 16: 178-186.

Stramiello M, Wagner JJ. 2010. Cocaine enhancement of long-term potentiation in the CA1 region of rat hippocampus: Lamina-specific mechanisms of action. Synapse 64: 644-648.

Tippens AL, Pare JF, Langwieser N, Moosmang S, Milner TA, Smith Y, Lee A. 2008. Ultrastructural evidence for pre- and postsynaptic localization of Cav1.2 L-type Ca2 + channels in the rat hippocampus. J Comp Neurol 506: $569-583$.

Toth K, Freund TF. 1992. Calbindin D28k-containing nonpyramidal cells in the rat hippocampus: Their immunoreactivity for GABA and projection to the medial septum. Neuroscience 49: 793-805.

Verney C, Baulac M, Berger B, Alvarez C, Vigny A, Helle KB. 1985. Morphological evidence for a dopaminergic terminal field in the hippocampal formation of young and adult rat. Neuroscience 14: 1039-1052.

Yang CR, Seamans JK. 1996. Dopamine D1 receptor actions in layers V-VI rat prefrontal cortex neurons in vitro: Modulation of dendritic-somatic signal integration. J Neurosci 16: 1922-1935.

Received March 5, 2012; accepted in revised form April 27, 2012. 


\section{Erratum}

Learning \& Memory 19: 294-299 (2012)

Dopamine induces LTP differentially in apical and basal dendrites through BDNF and voltage-dependent calcium channels

Sheeja Navakkode, Sreedharan Sajikumar, Martin Korte, and Tuck Wah Soong

The e-mail address for co-corresponding author Sheeja Navakkode in the above-mentioned article includes a typo. The correct e-mail address is: sheejanavakkode@yahoo.co.uk. 


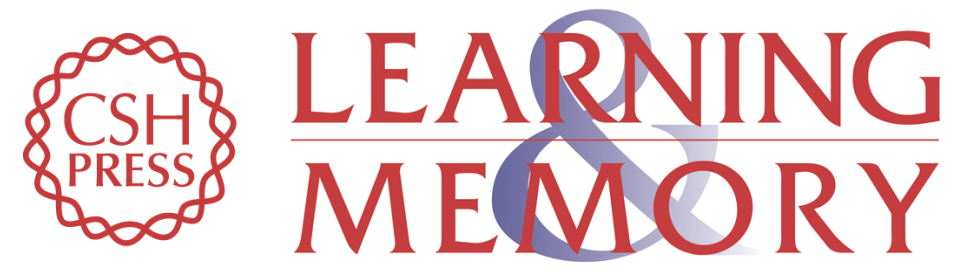

\section{Dopamine induces LTP differentially in apical and basal dendrites through BDNF and voltage-dependent calcium channels}

Sheeja Navakkode, Sreedharan Sajikumar, Martin Korte, et al.

Learn. Mem. 2012, 19:

Access the most recent version at doi:10.1101//m.026203.112

Related Content

References

Email Alerting Service

\section{License}

Erratum

Learn. Mem. August, 2012 19: 358

This article cites 43 articles, 19 of which can be accessed free at:

http://learnmem.cshlp.org/content/19/7/294.full.html\#ref-list-1

Articles cited in:

http://learnmem.cshlp.org/content/19/7/294.full.htmI\#related-urls

Receive free email alerts when new articles cite this article - sign up in the box at the top right corner of the article or click here. 